\title{
Potential of fermented papaya beverage in the prevention of foodborne illness incidence
}

\author{
${ }^{1 *}$ Koh, S.P., ${ }^{1}$ Aziz, N., ${ }^{1}$ Sharifudin, S.A., ${ }^{1}$ Abdullah, R., ${ }^{1}$ Hamid, N.S.A. and \\ ${ }^{2}$ Sarip, J. \\ 'Biotechnology and Nanotechnology Research Center, Malaysian Agricultural Research and \\ Development Institute (MARDI) Headquarters, P.O Box 12301, 50774 Selangor, Malaysia \\ ${ }^{2}$ Horticulture Research Center, Malaysian Agricultural Research and Development Institute \\ (MARDI) Headquarters, P.O Box 12301, 50774 Selangor, Malaysia
}

\author{
Article history: \\ Received : 12 April 2017 \\ Received in revised form \\ 7 April 2017 \\ Accepted : 8 April 2017 \\ Available Online : \\ 15 May 2017
}

\section{Keywords:}

Papaya

Fermentation

Foodborne pathogen

Minimum bactericidal

concentration

\section{DOI:}

http://doi.org/10.26656/ fr.2017.4.022

\begin{abstract}
Foodborne illness is recognized as an emerging infectious disease. The incidence of foodborne infections is common and the majority cases are undiagnosed or unreported. Apart from some diarrhea or minor gastrointestinal problem, some foodborne pathogenic microbes may cause death, particularly to those people with weakened immune system. In this study, we have developed a new fermented papaya beverage using symbiotic culture of yeast and acetic acid bacteria under controlled biofermentation process. An in-vitro assessment of fermented papaya beverage against few foodborne pathogenic microorganism was conducted to determine its minimum bactericidal concentration $\left(\mathrm{MBC}_{>99}\right)$. Three types of foodborne pathogen: Escherichia coli O157, Salmonella enterica serovar Typhimurium ATCC 53648, Salmonella enterica serovar Enteritidis (isolated from infectious chicken) were selected. From minimum bactericidal concentration $\left(\mathrm{MBC}_{>99}\right)$ assay, both fermented papaya pulp and leaves beverages have shown $100 \%$ killing rate against three selected foodborne pathogenic microbes. Inversely, non-fermented papaya pulp and leaves beverages indicated no inhibition at all. In fact, further dilution of fermented papaya pulp and leaves beverages demonstrated different degree of $\mathrm{MBC}_{>99}$ and brix value, but the $\mathrm{pH}$ value remained less than 3.5. These findings indicated the combination of soluble solid compounds presents in both fermented papaya beverage and product acidity play an important role in the inhibition of pathogenic microorganisms. The preliminary promising results of this work have shown that the great potential of fermented papaya beverages as a preventive measure to reduce the incidence of foodborne illness.
\end{abstract}

\section{Introduction}

Papaya (Carica papaya Linn.) is known as one of the most favorite fruit due to its nutritional, digestive and medicinal properties. It has rich source of phytonutrient content and high antioxidant capacity which contributing to its significant health profile. The flesh part of ripe papaya fruit has sweet and delicate taste, rich with multiple vitamins $(C$, $\mathrm{E}$ and $\mathrm{A}$ ) and contains an excellent source of folic acid, potassium, copper, phosphorous and iron. Many published clinical evidence had shown the presence of phytochemicals in papaya leaves contributes to its multiple functional role as a remedy for diabetes treatment (Juárez-Rojop et al., 2014), anti-inflammatory effect (Owoyele et al., 2008), immunomodulatory effects (Otsuki et al., 2010), chemopreventive effects (Tan et al., 2014), antiplasmodial effect (Ahmad et al., 2011) and analgetic activity (Hasimun et al. 2014).

Foodborne illnesses, often called as food poisoning, are referring as any illness resulting from the food spoilage of contaminated food, pathogenic bacteria, virus or parasites that contaminated foods, natural toxins from poisonous mushroom (Addis and Sisay, 2015). Onset of foodborne illness is very rapid with food intoxication and will cause very sick to infected people. Shiga toxin-producing Escherichia coli, Listeria monocytogenes, Vibrio vulnificus, Clostridium botulinum, and Salmonella infection are ranked as the most dangerous foodborne pathogens (Lim, 2002; MaCabe-Sellers and Beattie; 2004; Addis and Sisay, 2015; Zuraw, 2015). Even though these pathogenic microorganisms may not potentially lifethreatening to most healthy person, however, these pathogens can cause a severe and life-threatening 
illness, particularly dangerous to elderly people, pregnant women, children and immunocompromised people, including those with chronic liver disease, cancer or diabetes (MaCabe-Sellers and Beattie, 2004). In recent year, a considerable effort had been taken to find natural antimicrobial remedies that can inhibit the growth the bacterial and fungal growth in food to maintain food quality and shelf life. The use of food as antimicrobial agent has gained attention by the consumers and food industry. The potential of negative impact of synthetic preservatives on health has raised the interest among researchers to produce the natural antimicrobial compounds in foods.

To date, numerous scientifically studies had supported the clinical evidences on the effectiveness of fermented papaya preparation through natural fermentation process had confirmed a favourably effect in modulating immunological, haematological, neuroprotective, anti-inflammatory, antioxidants, prevention of diabetic complication from the progressive oxidative damage (Zhang et al., 2006; Aruoma et al., 2010; Marotta et al., 2012; Raffaelli et al., 2015; Barbagallo et al., 2015). In this study, we have developed a new biofermentation process to produce new fermented papaya phytonutrients beverage using defined starter cultures of yeast and acetic acid bacteria from MARDI's Collection of Functional Food Cultures (CFFC). Our main objective of this work was to investigate the effect of fermented papaya phytonutrients against the growth inhibition of few common foodborne pathogens with the aim to be served as preventive measures in reducing risk of foodborne illness incidence. The nonfermented papaya beverage samples were used as a control to examine the efficacy of fermented papaya phytonutrient against a broad range of foodborne pathogens.

\section{Materials and methods}

\subsection{Materials}

Papaya (Carica papaya Linn.) with the variety of Sekaki was bought from local papaya farm. Both papaya leaves and fruit were washed clean before proceeding to fast drying process to produce fruit powder and granule from the leaves and pulp part, respectively. The dried fruit powder and granule were packed in the aluminium bag and stored at the temperature of $4^{\circ} \mathrm{C}$ prior to fermentation process. Two strains of pathogenic microorganisms: E. coli O157 and Salmonella enterica serovar Typhimurium ATCC 53648 were bought from American Type Culture Collection, whereas, Salmonella enterica serovar Enteritidis was isolated from infectious chicken.

\subsection{Preparation of fermented beverage samples from dried papaya samples}

A total of $2.5 \%(\mathrm{v} / \mathrm{w})$ papaya leaves powder and $5 \%(\mathrm{w} / \mathrm{v})$ papaya pulp granule was prepared as non-fermented papaya leaves and papaya pulp beverage samples, respectively. Another set of fermented papaya leaves and pulp beverage samples was prepared with the same concentration of papaya leaves and papaya pulp suspension samples and were inoculated with $10 \%$ of the defined mixed culture of yeast (Dekkera sp.) and acetic acid bacteria (Gluronacetobacter sp.) from MARDI's Collection of Functional Food Cultures (CFFC) with the colony count of at least $1 \times 10^{8} \mathrm{CFU} / \mathrm{ml}$ and then incubated at $30^{\circ} \mathrm{C}$ for a duration of 4 days. The $\mathrm{pH}$ and Brix value of both fermented papaya leaves and pulp beverage samples were measured using $\mathrm{pH}$ meter and refractometer, respectively.

\subsection{Determination of minimum bactericidal concentration $\left(M B C_{>99}\right)$}

E. coli $\mathrm{O} 157, S$. enterica serovar Enteritidis and $S$. enterica serovar Typhimurium were cultured onto tryptone soy agar individually and incubated overnight. A loopful of foodborne pathogen culture from each tryptone soy agar was inoculated onto tryptone soy broth and then incubated at temperature of $37^{\circ} \mathrm{C}$ for $16 \mathrm{~h}$ at the agitation rate of $160 \mathrm{rpm}$ to obtain the suspension culture with the initial colony count of $10^{9} \mathrm{CFU} / \mathrm{ml}$. The $\mathrm{MBC}_{>99}$ for each microbe was determined using broth microdilution technique as described in Koh et al. (2016). Both non-fermented and fermented papaya leaves and papaya pulp beverage was used as an initial working concentration to determine its $\mathrm{MBC}_{>99}$. Each well contained $120 \mu \mathrm{l}$ of the test material in serially descending concentration. A growth control and sterility control were prepared also. A total of $20 \mu \mathrm{l}$ of inoculum containing foodborne pathogen suspension $\left(10^{9} \mathrm{CFU} / \mathrm{ml}\right)$ was added onto each well and was rotated using microtiter plate shaker before incubated at the temperature of $37^{\circ} \mathrm{C}$ for $24 \mathrm{~h}$. After incubation, the serial dilutions were performed in the eppendorf tube using micropipette and the plate count for each dilution was analyzed in triplicate. 


\subsection{Statistical analysis}

The experimental results were analyzed using SPSS software (SPSS statistics version 16). All data were expressed as the mean \pm standard deviation of triplicate analysis. A one way analysis of variance (ANOVA) at the 5\% significance level was used to determine significant differences $(P<0.05)$ between means.

\section{Results and discussion}

In this study, two types of fermented papaya phytonutrient beverages from the papaya leaves and pulp source were produced using controlled mixed cultures of yeast and acetic acid bacterial fermentation process. With the aid of microbial work, many biochemical changes on nutritive and anti-nutritive components of the papaya leaves and papaya pulp samples are manipulated through microbial enzymatic reactions and metabolisms. These processes can enhance the digestibility, bioavailability of nutrients and, enriched the bioactive components in the fermented papaya products, as being reported in many fermented foods (Russell and Duthie, 2011; Gumienna, et al., 2016). As expected, fermented papaya phytonutrients samples were found more palatable with better aroma and taste than nonfermented papaya phytonutrients samples with the aid of microbial work.

Three types of pathogenic microorganism were selected, which were: a) E. coli O157; b) S. enterica serovar Enteritidis and c) $S$. enterica serovar Typhimurium to examine the efficacy of fermented papaya leaves and pulp beverage sample against their growth inhibition rate. Different concentration of non-fermented and fermented papaya phytonutrients (papaya pulp and papaya leaves) were studied to determine the $\mathrm{MBC}_{>99}$ against E. coli O157, S. enterica serovar Enteritidis and S. enterica serovar Typhimurium. Generally, non-fermented papaya phytonutrients from both papaya leaves and pulp source showed no growth inhibition at all towards E. coli O157, S. enterica serovar Enteritidis and $S$. enterica serovar Typhimurium as summarized in Figure 1. Inversely, both fermented papaya leaves and pulp beverage samples exhibited different degree of growth inhibition rate against these specific types of pathogenic microorganisms (Figure 1a, $1 \mathrm{~b}$ and $1 \mathrm{c}$ ). In comparison to fermented papaya pulp, fermented papaya leaves beverage exhibited more higher growth inhibition rate against $S$. enterica serovar Enteritidis than E. coli $\mathrm{O} 157$ and S. enterica serovar Typhimurium with the $\mathrm{MBC}_{>99}$ value of $50 \%$ (Table
1). On the other hand, fermented papaya pulp showed growth inhibition preference towards $S$. enterica serovar Typhimurium than E. coli $\mathrm{O} 157$ and $S$. enterica serovar Enteritidis. With the $\mathrm{MBC}_{>99}$ value of $50 \%$, fermented papaya pulp beverage sample was capable to cause $100 \%$ killing rate against $S$. enterica serovar Typhimurium.

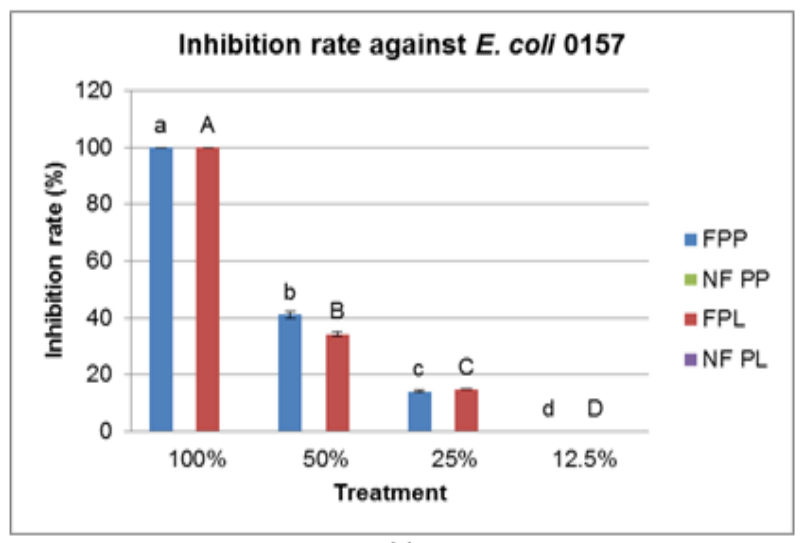

(a)

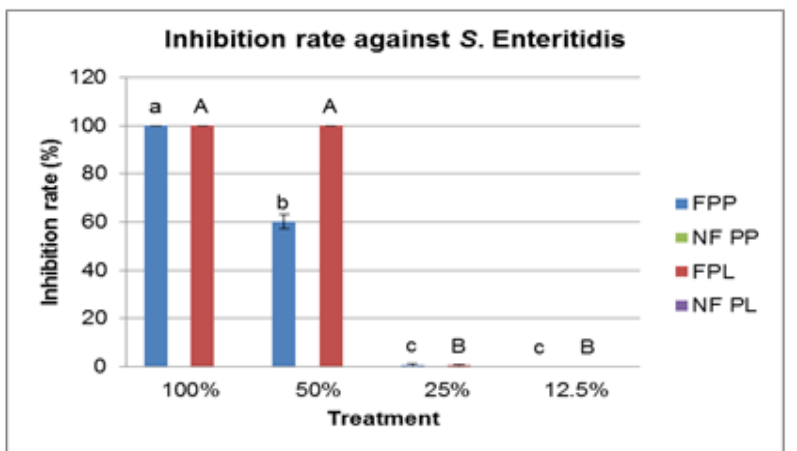

(b)

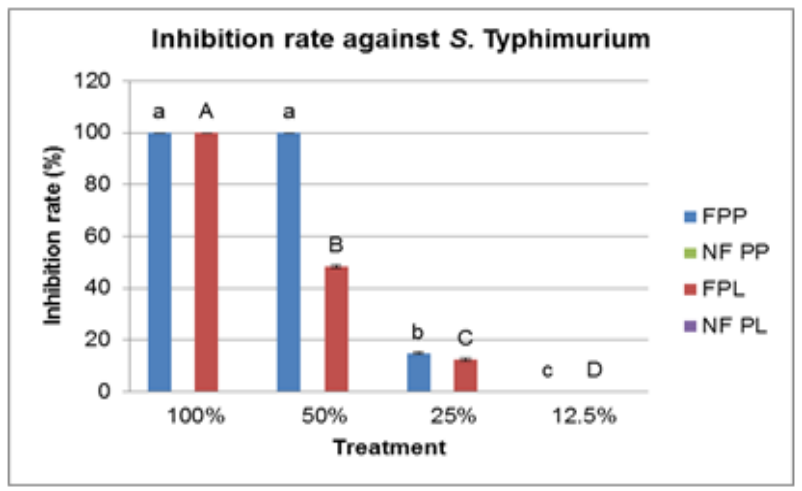

(c)

Figure 1. Inhibition rate against foodborne pathogens: a) $E$. coli O157; b) S. enterica serovar Enteritidis and c) S. enterica serovar Typhimurium using different concentration of papaya pulp (NF PP), papaya leaves (NF PL), fermented papaya pulp (FPP) and fermented papaya leaves (FPP) beverage samples 
Table 1. Minimum bactericidal concentration $\left(\mathrm{MBC}_{>99}\right)$ of non-fermented and fermented papaya leaves and pulp beverage against foodborne pathogens ${ }^{\mathrm{a}}$

\begin{tabular}{lcccc}
\hline Type of Pathogen & \multicolumn{4}{c}{ Minimum Bactericidal Concentration $\left(\mathrm{MBC}_{>99}\right)$} \\
\cline { 2 - 5 } & NF PL & FPL & NF PP & FPP \\
\hline $\begin{array}{l}\text { E. coli } \mathrm{O} 157 \\
\begin{array}{l}\text { S. enterica serovar } \\
\text { Enteritidis }\end{array}\end{array}$ & NIL & $100 \% \pm 0.0 \mathrm{~A}$ & NIL & $100 \% \pm 0.0 \mathrm{~A}$ \\
$\begin{array}{l}\text { S. enterica } \text { serovar } \\
\text { Typhimurium }\end{array}$ & NIL & $100 \% \pm 0.0 \mathrm{~B}$ & NIL & $100 \% \pm 0.0 \mathrm{~A}$ \\
\hline
\end{tabular}

${ }^{a}$ Each value in the Table represents the mean \pm standard deviation from triplicate analyses. Mean values with different superscripts in the same row are significantly different at $\mathrm{P}<0.05$.

Abbreviations: The $\mathrm{MBC}_{>99}$ is identified by determining the lowest concentration of substrate drink that reduces the viability of the initial pathogens inoculum by $99.9 \%$; papaya pulp (NF PP); papaya leaves (NF PL); fermented papaya pulp (FPP) and fermented papaya leaves (FPP)

Further dilution on both fermented papaya leaves and pulp beverage sample indicated the acidity of fermented papaya product was not the main cause of pathogen inhibition factor as the $\mathrm{pH}$ value demonstrated minor change even the fermented papaya product diluted up to $12.5 \%$ and the $\mathrm{pH}$ value remained below 3.5 (Figure 2a). However, the Brix value which measures the soluble solid content showed significant reduction when the fermented papaya beverage was diluted (Figure 2b). This phenomenon indicated the presence of soluble solid compounds such as soluble organic acids and phenolic acids in both fermented papaya beverages may contribute to its potent inhibition against foodborne pathogens. Past research findings have confirmed that many plant-derived polyphenolic compounds and organic acids with the variety of chemical composition showed their antimicrobial effectiveness against pathogens (Cueva et al., 2010; Stojković et al., 2013; Hawkins, 2014; Gyawali and Ibrahim, 2014). It was believed that the mixed culture of yeast and acetic acid bacteria had broken down the complex structure of phytochemicals in papaya leaves and pulp phytonutrients and changed their metabolite profile into more digestible and bioavailability phytonutrients. The presence of these functional bioactive metabolites in fermented papaya leaves and pulp beverage sample is the main contributing factor of their antimicrobial activity against selected foodborne pathogenic microorganisms when compared with non-fermented papaya leaves and pulp beverage samples.

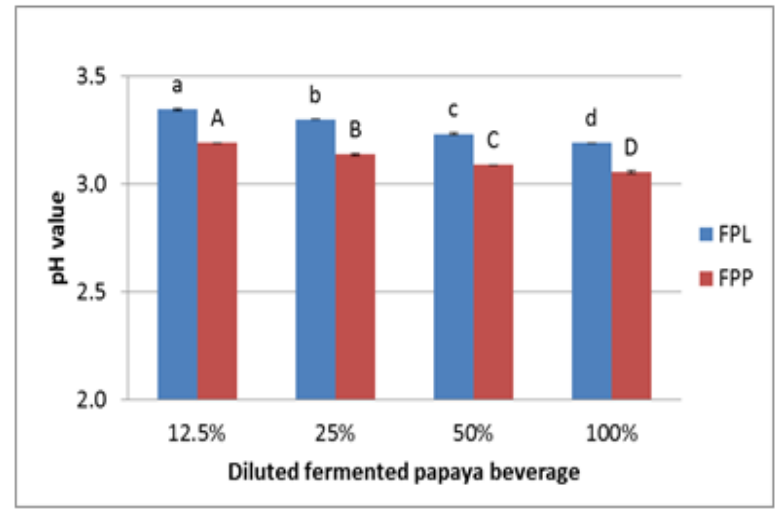

(a)

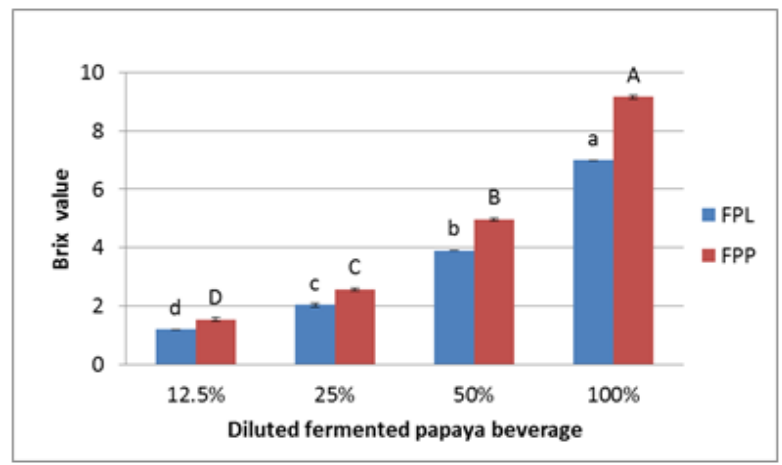

(b)

Figure 2. The changes of: a) $\mathrm{pH}$ value; b) Brix value when both fermented papaya pulp (FPP) and fermented papaya leaves (FPP) beverage samples were diluted up to $12.5 \%$

\section{Conclusions}

Both fermented papaya phytonutrients beverage produced from papaya leaves and pulp source have exhibited the promising results on growth inhibition against selected pathogenic microorganisms, which were E. coli O157, S. enterica serovar Enteritidis and $S$. enterica serovar Typhimurium. This finding indicated the potential of fermented papaya phytonutrients in reducing risk of foodborne illness. We believed that the fermented papaya phytonutrients can be served as a daily nutritional supplement for maintaining good health to minimize food poisoning incidence. Future work will be focused on the study of the metabolite papaya phytonutrient profile changes after fermentation and identify the bioactive compounds that contributing to its growth inhibition against pathogenic microorganisms.

\section{Conflicts of interest}

The authors declare no conflict of interest. 


\section{Acknowledgement}

This study was financially supported by Horticulture Research Centre, MARDI under Government Development Fund RMK-11 (P21003004050001).

\section{References}

Addis, M. and Sisay, D. (2015). A review on major food borne bacterial illness. Journal of Tropical Diseases Doi: 10.4176/2329891X.1000176.

Ahmad, N., Fazal, H., Ayaz, M., Abbasi, B.H., Mohammad, I. and Fazal, L. (2011). Dengue fever treatment with Carica papaya leaves extracts. Asian Pacific Journal of Tropical Biomedicine, 1, 330-333.

Aruoma, O.I., Hayashi, Y., Marotta, F., Mantello, P., Rachmilewitz, E. and Montagnier, L. (2010). Applications and bioefficacy of the functional food supplement fermented papaya preparation. Toxicology, 278, 6-16.

Barbagallo, M., Marotta, F. and Dominguez, L. J. (2015). Oxidative stress in patients with Alzheimer's disease: effect of extracts of fermented papaya powder. Mediators of Inflammation http://dx.doi. org/10.1155/2015/624801.

Cueva, C., Moreno-Arribas, M. V., Martín-Álvarez, P. J., Bills, G., Vicente, M. F., Basilio, A., Rivas, C. L., Requena, T., Rodríguez, J. M. and Bartolomé, B. (2010). Antimicrobial activity of phenolic acids against commensal, probiotic and pathogenic bacteria. Research in Microbiology, 161, 372-382.

Gumienna, M., Szwengiel, A. and Górna, B. (2016). Bioactive components of pomegranate fruit and their transformation by fermentation processes. European Food Research and Technology, 242(5), 631-640.

Gyawali, R. and Ibrahim, S. (2014). Natural products as antimicrobial agents. Food Control, 46, 412-429.

Hasimun, O., Suwendar, and Ernasari, G. I. (2014). Analgetic activity of papaya (Carica papaya L.) leaves extract. Procedia Chemistry, 13, 147-149.

Hawkins, S. G. (2014). Antimicrobial activity of cinnamic acid, citric acid, cinamaldehyde and levulinic acid against foodborne pathogens. University of Tennessee Honors Thesis Projects. Retrieved from: http:// trace. tennessee.edu/utk_chanhonorproj/1701.

Juárez-Rojop, I. E., Tovilla-Zárate, C. A., AguilarDomínguez, D. E., Roa-de la Fuente, L. F., LobatoGarcía, C. E., Blé-Castillo, J. L., López-Meraz, L., Díaz-Zagoya, J. C. and Bermúdez-Ocaña, D. Y. (2014). Phytochemical screening and hypoglycemic activity of Carica papaya leaf in streptozotocin-induced diabetic rats. Revista Brasileira de Farmacognosia, 24, 341-347.

Koh, S. P., Harun, D., Mat-Amin, M. and Long, K., 2016. Enhanced virgin coconut oil (EVCO) as natural postmiliking test germicide to control environmental mastitis pathogens. International Journal of Biotechnology for Wellness Industries, 5, 128-134.
Lim, V. K. E. (2002). Foodborne diseases in Malaysia. The Medical Journal of Malaysia, 57, 1-2.

Marotta, F., Celep, G. S., Cabeca, A. and Polimeni, A. (2012). Novel concepts on functional foods and nutrigenomics in healthy aging and chronic diseases: a review of fermented papaya preparation research progress. Functional Foods in Health and Disease, 2, 120-136.

McCabe-Sellers, B. J. and Beattie, S. E. (2004). Food Safety: Emerging trends in foodborne illness surveillance and prevention. Journal of the American Dietetic Association, 104, 1708-1717.

Otsuki, N., Dang, N. H., Kumagai, E., Kondo, A., Iwata, S. and Morimoto, C. (2010). Aqueous extract of Carica papaya leaves exhibits anti-tumor activity and immunomodulatory effects. Journal of Ethnopharmacology, 127, 760-767.

Owoyele, B. V., Adebukola, O. M., Funmilayo, A. A. and Soladoye, A. O. (2008). Anti-inflammatory activities of ethanolic extract of Carica papaya leaves. Inflammopharmacology, 16, 168-173.

Raffaelli, F., Nanetti, L., Montecchiani, G., Borroni, F., Salvolini, E., Faloia, E., Ferretti, G., Mazzanti, L. and Vignini, A. (2015). In vitro effects of fermented papaya (Carica papaya, L.) on platelets obtained from patients with type 2 diabetes. Nutrition, Metabolism and Cardiovascular Diseases, 25, 224-229.

Russell, W. and Duthie, G. (2011). Plant secondary metabolites and gut health: the case for phenolic acids. Proceedings of the Nutrition Society, 70, 389-396.

Stojković, D., Petrović, J., Soković, M., Glamočlija, J., Kukić-Marković, J. and Petrović, S. (2013). In situ antioxidant and antimicrobial activities of naturally occurring caffeic acid, p-coumaric acid and rutin, using food systems. Journal of the Science of Food and Agriculture, 93(13), 3205-3208.

Tan, S. A., Goya, L., Ramanathan, S., Sulaiman, S. F., Alam, M. and Navaratnam, V. (2014). Chemopreventive effects of standardized papaya leaf fraction on oxidatively stressed human liver cells. Food Research International, 64, 387-395.

Zhang, J., Mori, A., Chen, Q. and Zhao, B. (2006). Fermented papaya preparation attenuates $\beta$-amyloid precursor protein: $\beta$-amyloid-mediated copper neurotoxicity in $\beta$-amyloid precursor protein and $\beta$-amyloid precursor protein Swedish mutation overexpressing SH-SY5Y cells. Neuroscience, 143, 63-72.

Zuraw,1.(2015). The 5mostdangerous foodbornepathogens. Retrieved from Food Safety News Website: Http:// www.foodsafetynews.com/2015/09/the-5-mostdangerous-foodborne pathogen/\#WG8BK1N97IU. 